\title{
AURORA LUQUE, GAVIERA Y NÓMADA
}

\author{
AURORA LUQUE, SAILOR AND NOMAD
}

Josefa Álvarez

Le Moyne College

alvarej@lemoyne.edu

\begin{abstract}
Aurora Luque es, sin lugar a dudas, una de las voces más destacadas del panorama poético actual. Autora de nueve poemarios hasta la fecha, entre los que sobresalen títulos como Carpe noctem (1994, Premio Rey Juan Carlos), Camaradas de Ícaro (2003, Premio Fray Luis de León), La siesta de Epicuro (2008, Premio Generación del 27) y más recientemente Personal \& político (2015), acaba de recibir el prestigioso premio Loewe con el poemario Gavieras. Su obra ha sido, por otra parte, frecuentemente antologada (dan buena muestra de ello Carpe amorem, Fabricación de las islas, con prefacio de Caballero Bonald, Médula o Los limones absortos, en edición bilingüe italiano-español) y vertida a diferentes idiomas como el inglés, el francés o el griego moderno, además de al italiano.

A través de esta conversación trataremos de dar un breve repaso no solo a su trayectoria literaria, sino a otras facetas de su trabajo como la crítica feminista y la traducción.
\end{abstract}

Josefa Álvarez: Aurora, tu formación como filóloga clásica ha condicionado en gran medida tu universo poético, como percibimos ya desde varios de tus títulos. ¿Qué has hallado en los clásicos grecorromanos que eches a faltar en estos tiempos y cuál consideras que es la principal enseñanza que aquellos nos han legado?

Aurora luque: Mi necesidad de los clásicos es anterior a la formación como filóloga clásica. Arranca de un desasosiego existencial en la adolescencia. A mi generación la formaron desde principios católicos rígidos y poco dialogantes que a la niña inquieta, lectora y soñadora que fui le resultaban muy poco satisfactorios. Aquel catolicismo era hostil al erotismo, al ansia de libertad, al orgullo de emprender tareas intelectuales ambiciosas, a todo deseo de explorar, de viajar y hasta de bailar. Por todas partes te argumentaban o amenazaban con conceptos siniestros o restrictivos: penitencia, culpa femenina original, pecado mortal, sacrificio, martirio, calvario, virginidad ideal, maternidad como único fin vital... Por eso, a los quince años, me reconocí inmediatamente en aquel capítulo de Ocnos en el que Cernuda habla del deslumbramiento que supuso para él el 
encuentro con la mitología griega: la sospecha de una alegría, de un gusto por la belleza y por la vida que en el cristianismo no se hallaban. Los griegos me reconciliaron con la naturaleza y con el mundo y me ayudaron a no fiar mi existencia a un Dios iracundo y mandón que castigaba a los malos y premiaba a los buenos. Yo no era de las buenas.

JA: Dentro de la herencia clásica, el mito es uno de los pilares fundamentales de tu poesía. En mi opinión haces de él un elemento maleable y actual, pero, ¿podrías explicarnos en qué medida dota de pleno sentido a esta sin desvincularla del mundo de hoy?

AL: La mitología ha funcionado en Occidente como una Biblia paralela para los artistas. Es una materia no dogmática: los griegos la hicieron flexible desde el comienzo, maleable; la enriquecían las variantes, porque no pretendían una Verdad absoluta, sino dar cuenta de la complejidad maravillosa y profunda del mundo y de sus seres. El mito es un recurso reciclable, perpetuamente renovable, reescribible. Sirve para sugerir interpretaciones o para señalar abismos de la condición humana tanto en el siglo XXI como en los siglos de Virgilio o de Eurípides o de Calímaco. Es un material elástico. En estado fluido, el mito es útil para la escritura de la poesía. En estado rígido, solo conseguiremos réplicas arqueológicas.

JA: Continuando con el mito... Más de una vez has dicho, como lo haces poéticamente en el poemario que se hace eco de ello en su título, que los poetas han de ser "Camaradas de Ícaro". ¿En qué sentido y por qué?

AL: En el sentido del riesgo. Ícaro desobedece a su sensato padre Dédalo y opta por probar el vuelo. En la lectura griega, Ícaro peca de hybris y se aleja de la deseable mesura. En la poesía hay que construirse unas alas propias e intentar explorar el otro lado de las cosas y el otro lado del lenguaje. Aunque caigas después, derrotada y exhausta.

JA: El deseo y el cuerpo son importantes ejes vertebradores de tu obra y ambos están intrínsecamente vinculados a la noche. ¿Cómo se convierte tu Carpe noctem en precepto vital en ella y cómo convive con tu reclamo de la "Poética solar" (evocadora de la "erótica solar" del filósofo francés Michael Onfray) de la que hablas en la antología Médula?

AL: Carpe noctem amplifica el lema horaciano. No recojas solo la cosecha del día; corta también los frutos de la noche, que es tu tiempo más tuyo, más libre y creativo y menos sometido a rutinas. Non solum "dies" sed etiam "nox". Onfray en su Teoría del cuerpo enamorado parecía hablarme como colega del primer Ovidio, como partícipe del cenáculo de Campania, como un portavoz del Lucrecio más lúcido y materialista, como cerdito de la piara de Epicuro. Como antiplatónico y antidualista, en suma. Intenta imaginar una vida desembarazada de la ética conformista de raíz estoica y cristiana que sigue modulando en nuestros días 
nuestras estabuladas existencias. Y ahí propone una erótica solar, un hedonismo austero que comparto como ideal y que podría tener su correlato en la escritura.

JA: La poeta Safo quizá es la figura en la que mejor confluyen tu pasión por los clásicos y la prevalencia del deseo en tu poética. Su huella es abierta en ocasiones, soterrada en otras, pero siempre rastreable. ¿Qué vínculo os une a ambas no solo como poetas sino también como mujeres?

AL: Encontré pronto a Safo, a principios de los años ochenta, y con la traducción de Juan Ferraté supe que estaba ante una poeta excepcional. Estoy dedicando el resto de mi vida a traducirla y leerla más a fondo. Ella sí que fue camarada de Ícaro: se atreve a cuestionar, sola en el año 600 a. C., los valores heroicos y militares de Homero. Lo más bello que hay en el mundo no es una escuadra de barcos o una formación de jinetes o de soldados. Lo más hermoso es lo que cada cual ama. Desafía también la asignación de roles afectivos y aun familiares: el amor hace a Helena olvidar a su esposo y a su hija y a pesar de ello el amor es hermoso. Como poeta es prodigiosa: tiene la audacia de reconvertir un himno ritual a Afrodita en un poema íntimo de soledad y deseo amoroso, por ejemplo. Habla del erotismo con precisión y fuerza. Lleva a los poemas la memoria de las experiencias vividas y la reactualiza. Tiene esa facilidad pasmosa de los genios para cantar con nitidez lo más hondo y complejo, como lo hacen Jorge Manrique o Machado. Qué suerte que su poesía haya sobrevivido, aunque sea de modo fragmentario. Sí, es mi maestra número uno.

JA: Tampoco podemos olvidar a Epicuro, que da título incluso a uno de tus poemarios. ¿Podría decirse de ti que eres una epicúrea posmoderna? ¿Cabe en nuestro tiempo un nuevo jardín?

AL: Pues ya quisiera yo merecer ese título. Ahora trabajo sobre Emilio Lledó, que ha sido nombrado Autor del Año 2020 en Andalucía. Me quedo con su valoración de Epicuro. Frente a los premios o castigos ultraterrenos, Epicuro alza "un mensaje revolucionario. Con ello alumbró, de una luz distinta, la democratización del cuerpo humano, el apego a la vida y a la pobre y desamparada carne de los hombres, entre cuyos sutiles y misteriosos vericuetos alentaban la alegría y la tristeza, la serenidad y el dolor, la generosidad y la crueldad. Y, sobre todo, imaginó una educación y política del amor, única forma posible y esperanzada de seguir viviendo". Así Lledó explica la revolución epicúrea, que era tan subversiva que se dieron prisa en aniquilarla y cubrirla de olvido e inmundicia. Los tres monoteísmos principales instan a aplazar la vida, a sustituir la existencia presente y corporal por la vida eterna. Epicuro nos invita a perder el miedo a la muerte ("Si la muerte nos horroriza, es porque aquello en lo que estamos, la vida, es un bien, o al menos puede serlo", dice Lledó) y a disfrutar de los "regalos brillantes de la naturaleza: la maravillosa organización del cuerpo humano, la fraternidad de los ojos con la luz, de la piel con el aire", prosigue el filósofo sevillano. Sí, cabe un nuevo jardín. Yo al menos intento construir el mío, tanto en la poesía como en 
la vida. Un huerto en este mundo para disfrutar del tiempo humano en sus más bellas formas: la amistad, por ejemplo.

JA: Personal \& Político, Cuaderno de Flandes, ambos del 2015, y los poemas contenidos en dos cuadernillos de reciente publicación, Orinque y Protesta de mar (2017), parecen marcar un antes y un después en tu poesía. Como Francisco Díaz de Castro pone de relieve en un trabajo recién publicado, tiendes en ellos a poemas más extensos, más narrativos, y parece que indagas más a fondo en la realidad actual. ¿Qué puedes decir al respecto?

AL: Sí, emprendí una serie de poemas menos concentrados, dejando entrar segmentos narrativos que antes mantuve siempre fuera. Ahora bien, tengo serias dudas sobre qué cosa sea "la realidad actual". Toda poesía, si no es un mero ejercicio verbal y recreativo, es actual. Se sitúa en el presente y desde ahí dialoga o contempla o analiza. Me importa el Epicuro con el que puedo "discutir" aquí y ahora, o la lección de Dickinson desde su casa americana, o pregunto a los Bowles sobre su errancia. Me llevo a mi poema a un héroe de una serie de televisión porque me está mostrando mentiras sobre la identidad y trampas de la sociedad de mi tiempo. Y mi tiempo es convulso, y las convulsiones colectivas afectan a mi manera de entender la memoria, la escritura, la ciudad, las relaciones con los otros. Quiero decir que no selecciono previamente las realidades desde las que escribo.

JA: No obstante, un tema que vuelve con fuerza en estos últimos poemarios es la memoria, firme presencia en toda tu obra. Es, con el paso del tiempo y con las inclemencias de este, probablemente más necesaria que nunca, ¿no es así?

AL: El cerebro se va convirtiendo cada vez más en almacén de cosas vividas, en archivo, en disco duro casi saturado. Ciertamente la piel pierde elasticidad los huesos y los ojos se van cansando, pero la vida archivada, los libros leídos y sedimentados son un tesoro incalculable. Ayer escuchaba a Agnès Varda en una entrevista: "Oh, vejez amiga. Me gusta bastante ser vieja, creo". Los recuerdos acumulados acompañan; la vida vivida y las lecciones que te ha ido dando la poesía te enseñan a seleccionar, a disfrutar mucho más de lo que de verdad importa. Entre los treinta y cuarenta se pierden muchas magníficas energías en vivir la vida que quieren otros, no la tuya. ¿Se canta lo que se pierde? Solo en parte. Duele mucho lo perdido, pero no me veo componiendo elegías lloronas.

JA: Lo que igualmente apreciamos es sin duda que tu voz es más y más reivindicativa desde un posicionamiento del que nunca te has apartado, pero que parece ahora emerger con más fuerza: el feminismo. ¿Te sientes amparada por esta marea impresionante de mujeres que se ha movilizado en España? ¿Qué separa o qué une a poemas anteriores como tu famoso "Aviso de correos" y a otros más recientes como "Disidanzas"? 
$\mathrm{AL}$ : Me siento feliz de vivir este momento histórico en el que el feminismo se ha convertido en la única revolución progresista, sostenida, transversal, teórica y práctica que está vigente y extendida por todo el planeta. No hay vuelta atrás. El nuevo feminismo ha llegado para señalar que el emperador va desnudo (y el productor, y el director de empresa y el catedrático... todos aquellos que se aprovecharon de las posiciones de poder que les regalaba un patriarcado incuestionado). Ahora revisamos, además, el pasado, incluso el reciente. Me quedé pasmada hace unas noches al ver cómo se había olvidado interesadamente a la gran pionera del cine, la francesa Alice Guy.

Por mi educación familiar llevo tiempo en esas lides. Yo misma me impuse un tema feminista de memoria de licenciatura en 1986 cuando no habían entrado aún en la universidad andaluza los estudios de género: "La poesía compuesta por mujeres en la Grecia clásica y helenística", un estudio que por cierto está en la base de una traducción que aparecerá en marzo de 2020 en la mítica colección Austral (Grecorromanas. Lírica superviviente). Mi poema "Aviso de Correos" de 1997 es una ficción sobre la necesidad de un recambio del lenguaje: ya no vale el contenido de la antigua caja de Pandora. Imaginemos que dentro hay herramientas para desmontar la misoginia de los mitos eternos patriarcales: sus nocivas formas de entender el amor, sus mordazas gramaticales, la sumisión como virtud femenina, la falta de autoestima literaria...

JA: Otra constante en tu poesía es el viaje, tanto literal como metafórico a través de la lectura, por ejemplo. Vinculado en cierta medida a él hay un poema en Personal \& político fundamental para tu poesía posterior, tanto la de los cuadernos mencionados anteriormente (Orinque y Protesta de mar) como la de ese nuevo y premiado poemario. Me estoy refiriendo a "La palabra gaviera". ¿Qué es una "gaviera" y qué papel juega esta en tu poesía última? ¿Puede de alguna manera vincularse a la figura del nómada que propugna, por ejemplo, Braidotti? ¿Es esta, en el sentido que la filósofa defiende, una figura que subvierte las condiciones establecidas?

AL: La gaviera es la mujer que atiende al horizonte, bien en sentido literal, desde la gavia del barco, bien metafórico: la que está pendiente de lo que ocurre en los confines, la que vigila todo el mar y lo relata. La palabra no existía en femenino en el DRAE, hasta que la editora Ana Santos Payán promovió una recogida de firmas para que fuese incluida. La gaviera es viajera; trasciende el límite de la habitación propia woolfiana y aun de la casa propia. La gaviera está en movimiento sobre rutas fluidas, inestables. La gaviera es hermana de las nuevas flâneuses, de las peregrinas, de las exiliadas, de las espigadoras... De todos esos nomadismos escribo en mi nuevo libro, Gavieras. La teoría de Braidotti es una de las contestaciones más sugerentes a la preeminencia empobrecedora e inamovible del etno-, logo-, euro- y falocentrismo vigentes. Es ya inviable definir la identidad asociándola a un estado, una lengua, una bandera. Por ello resulta apasionante incluso mirar al pasado para descubrir los casos y los modos en que esa identidad fluida de las mujeres recorría sus propios caminos diseñados libre y secretamente, sorteando las polarizaciones paralizadoras: aventuras como la de Eleonora Fonseca Pimentel o la de la viajera y peregrina Poimenia. 
JA: Braidotti habla del nómada como del que continuamente deviene, nunca se establece. En términos deleuzeanos "hace rizoma", abandonando la verticalidad. ¿Crees que tanto tu vida como tu escritura son rizomáticas, son raíces que se multiplican y huyen de las tradicionales dualidades impuestas durante tanto tiempo al género femenino?

AL: Quisiera creer que sí. Ese devenir rizomático ilumina relaciones, zonas fluidas que antes no habían obtenido lenguaje, no habían sido establecidas ni nombradas. La ordenación falogocéntrica del mundo deja en la sombra incluso la semántica del cuerpo femenino (como sugerí en mi "Oda a la ciprina"). La intolerable jerarquía que marca el masculino presuntamente universal sigue teniendo consecuencias lingüísticas y gramaticales. La presión de la norma continúa. Cuesta crecer y expandirse. El patriarcado sigue inventando monstruos. [...]

JA: Muy conectado al nomadismo está el mar. El mar está una y otra vez presente en tu poesía. El mar como destino, el mar de Grecia, el mar de tu infancia. Mar y viaje, mar y deseo... ¿Puedes hablarnos un poco de esa multiplicidad de valores del mar en tu obra?

AL: Sí, es una de mis grandes pasiones. Me calma, me hace sentir libre, me hace imaginar historias, viajes y poemas. Y, especialmente, el mar de los griegos. Por eso dediqué varios años a traducirlo en el volumen Aquel vivir del mar.

JA: No quisiera cerrar esta conversación sin mencionar otras facetas de tu trabajo igualmente destacables de las que ya has ido haciendo alguna mención: tu dedicación a la traducción, en particular, pero no solo, de clásicos grecolatinos entre los que destacamos a Safo (ya vas por la tercera edición de su obra en Acantilado), y tu labor como crítica literaria, centrada en particular en el rescate de autoras olvidadas como la cubana Mercedes Matamoros o la malagueña María Rosa de Gálvez. ¿Influyen estas tareas en tu creación poética? ¿Existen vasos comunicantes entre unas y otra? ¿Cómo las percibes?

AL: Lo vivo como un compromiso político. Cuando compruebas que la obra de una dramaturga tan valiosa como la de María Rosa de Gálvez se desdeñó sin ser leída solo porque los críticos de turno consideraron intolerables las costumbres de la autora, me veo en la obligación de detenerme y estudiarla. Aprendo mucho en el camino.

La traducción, por otro lado, es para mí un ejercicio de mantenimiento. Traducir poesía -solo traduzco la poesía que yo decido- me ayuda a desentrañar los mecanismos, los secretos de laboratorio de otros poetas. No traduzco solo a mujeres, obviamente. Me he ocupado de Catulo y Meleagro en monográficos y de casi todos los poetas griegos antiguos en Los dados de Eros. Antología de poesía erótica griega (Hiperión, 2000) y el ya antes aludido Aquel vivir del mar. El mar en la poesía griega (Acantilado, 2015). 
JA: Acabas de publicar en la editorial Vaso Roto la traducción al español de la traducción inglesa que la poeta canadiense Anne Carson ha realizado de la obra de la poeta de Lesbos. ¿Qué desafíos has tenido que afrontar con este proyecto? ¿Has descubierto nuevos matices en la poesía de Safo a través de la lectura que de ella hace Carson?

AL: Me fascinaba Carson por dos cosas: como ensayista agudísima en su libro Eros. Poética del deseo y como poeta descaradamente libre y exploradora en libros como Decreación. He descubierto cómo un traductor-poeta no puede de ninguna manera desembarazarse de su poética a la hora de traducir. Impone sus preferencias, sus guiños, sus pequeños caprichos incluso. En las notas, he sonreído en los momentos en los que Carson enfrenta con ácida ironía los excesos académicos de la erudición clásica. Es una gran poeta Anne Carson.

JA: Como traductora que eres, ¿qué sensaciones te genera ver tu obra traducida a otros idiomas? ¿Te ha ayudado leer las traducciones que se han hecho de tu poesía a reflexionar sobre esa vertiente de tu trabajo?

AL: No dedico demasiado tiempo a compararla. Solo compruebo que no hay discrepancias grandes de sentido y, si conozco los ritmos de la lengua a que se traduce, leo los poemas en voz alta. Creo que un poema traducido ya tiene una vida propia y casi autónoma. Confío en los traductores.

JA: Al margen de en la traducción y crítica literaria, has hecho alguna pequeña incursión también en el mundo del teatro. ¿Podemos esperar nuevas creaciones en ese ámbito? ¿Cuál ha sido tu experiencia en él y en qué medida te ha enriquecido como autora e incluso como mujer?

AL: Es uno de esos retos que te proponen y no sabes ni quieres renunciar a ellos. Yo jamás había participado en empresa teatral alguna (salvo a los siete u ocho años, cuando se me ocurrió "dirigir" por mi cuenta con unas amiguitas una representación de La Cenicienta). Se trataba de escribir un texto en el centenario del nacimiento de Ingmar Bergman para un ciclo que se llevaría a escena en Málaga. Un monólogo. Descargué veintiocho películas y documentales bergmanianos en Filmin y me empapé morbosamente del mundo del sueco en pleno agosto andaluz de 2018. Quería comprobar si Bergman seguía siendo tan perturbador como me lo había parecido hace tres décadas. Y sí, lo es. Hablé con él mediante una médium, una presunta actriz secundaria de su cine que se enfrentaba a la locura y a la muerte. Media hora con Bergman, en obvio homenaje a las Cinco horas con Mario de Delibes. Lo representó fieramente una estupenda actriz, Toñi Martín.

JA: Para terminar, ¿qué nos deparan tus Gavieras? ¿Vamos a encontrar a esa nómada que siempre da un paso más allá como ya nos ha demostrado en sus entregas poéticas desde el 2015?

AL: Serán las gavieras mismas las que deban decirlo... 